Sitzungsberichte

der Akademie der Wissenschaften der DDR

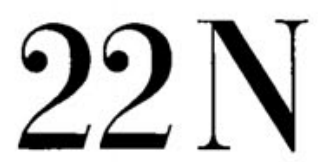

Mathematik - Naturwissenschaften - Technik

1981

Ausgewählte

Forschungsergebnisse

der Physik

Dem Wirken Robert Rompes gewidmet

AKADEMIE-VERLAG - BERLIN 

Sitzungsberichte

der Akademie der Wissenschaften

der DDR

Jahrgang $1981 \cdot$ Nr. 22/N

Mathematik - Naturwissenschaft - Technik

\title{
Ausgewählte Forschungsergebnisse der Physik
}

\author{
Dem Wirken Robert Rompes gewidmet
}

AKADEMIE-VERLAG · BERLIN 1983 
Vorträge des Kolloquiums anläßlich

des 75. Geburtstages von Robert Rompe,

Ordentliches Mitglied der Akademie der

Wissenschaften der DDR, am 11. September 1980

Herausgegeben im Auftrage

des Präsidenten der Akademie

der Wissenschaften der DDR

von Vizepräsident Prof. Dr. Heinrich Scheel

ISSN 0138-3956

Erschienen im Akademie-Verlag, DDR-1086 Berlin, Leipziger Str. 3-4

(C) Akademie-Verlag, Berlin 1983

Lizenznummer: $202 \cdot 100 / 53 / 82$

Gesamtherstellung: VEB Druckhaus Köthen

Bestellnummer: 7630800 (2010/81/22/N) · LSV 1105

Printed in GDR

DDR 10,- M 